Working Paper/Document de travail

2009-22

\title{
Productivity, the Terms of Trade, and the Real Exchange Rate: The Balassa- Samuelson Hypothesis Revisited
}

by Ehsan U. Choudhri and Lawrence L. Schembri 
Bank of Canada Working Paper 2009-22

August 2009

\title{
Productivity, the Terms of Trade, and the Real Exchange Rate: The Balassa- Samuelson Hypothesis Revisited
}

by

\author{
Ehsan U. Choudhri ${ }^{1}$ and Lawrence L. Schembri ${ }^{2}$ \\ 1Department of Economics \\ Carleton University \\ Ottawa, Ontario, Canada K1S 5B6 \\ ehsan_choudhri@carleton.ca \\ 2International Economic Analysis Department \\ Bank of Canada \\ Ottawa, Ontario, Canada K1A 0G9 \\ Ischembri@bankofcanada.ca
}

Bank of Canada working papers are theoretical or empirical works-in-progress on subjects in economics and finance. The views expressed in this paper are those of the authors.

No responsibility for them should be attributed to the Bank of Canada. 


\section{Acknowledgements}

The authors would like to thank Wei Dong, Robert Lafrance and Philipp Maier for helpful comments. 


\begin{abstract}
The paper examines how the Balassa-Samuelson hypothesis is affected by a modern variation of the standard model that allows product differentiation (within the traded and nontraded goods sectors) with the number of firms determined exogenously or endogenously. The hypothesis is found to be fragile in the modified framework. Small variations in the elasticity of substitution between home and foreign traded goods (within the range of estimates suggested in the literature), for example, can make the effect of a traded-goods productivity improvement on the real exchange rate negative or positive, as well as small or large. This result provides a potential explanation of the mixed empirical results that have been obtained on the relationship between productivity and the real exchange rate.

JEL classification: F41, F31

Bank classification: Exchange rates; Productivity
\end{abstract}

\title{
Résumé
}

Les auteurs évaluent l'incidence qu'a sur l'hypothèse de Balassa-Samuelson une variante moderne du modèle de référence qui autorise une différenciation des produits (au sein des secteurs des biens échangeables et non échangeables) et une détermination exogène ou endogène du nombre d'entreprises. L'hypothèse, dans ce cadre modifié, apparaît fragile. De menues variations de l'élasticité de substitution entre les biens échangeables fabriqués au pays et ceux fabriqués à l'étranger (dans les limites des estimations proposées dans la littérature), par exemple, peuvent rendre négatif ou positif l'effet d'une amélioration de la productivité dans le secteur des biens échangeables sur le taux de change réel et atténuer ou amplifier cet effet. Ce résultat explique peut-être la diversité des observations empiriques recueillies à propos de la relation entre la productivité et le taux de change réel.

Classification JEL : F41, F31

Classification de la Banque : Taux de change; Productivité 


\section{Introduction}

One popular and enduring explanation of how sectoral productivity changes affect the real exchange rate is based on the well-known hypothesis of Balassa (1964) and Samuelson (1964). ${ }^{1}$ The basic version of this hypothesis assumes that the purchasing power parity holds for traded goods, and predicts that an improvement in the relative productivity of traded to nontraded goods in a country vis-a-vis its trading partner will increase the real value of its currency via an increase in the relative price of nontraded to traded goods. The time-series evidence in support of this hypothesis, however, is mixed (e.g., see Rogoff, 1996). ${ }^{2}$ Short-run deviations from the Balassa-Samuelson effect could arise from nominal rigidities. However, even in tests that focus on the long-run effects, the Balassa-Samuelson model does not fare well in several respects. There are long-run departures from the purchasing power parity for traded goods (Canzoneri, Cumby, and Diba, 1999). ${ }^{3}$ Estimates of the effect of the traded-goods productivity differential on the real exchange rate, moreover, tend to be smaller than that predicted by the theory, and in some studies are insignificant or have the wrong sign. ${ }^{4}$

This paper examines whether the mixed results on the Balassa-Samuelson hypothesis can be explained by a variation of the model that introduces differentiation between home and foreign traded goods along the lines of Armington (1969) and

\footnotetext{
${ }^{1}$ This hypothesis is also associated with Harrod (1933).

${ }^{2}$ Cross-sectional evidence on the association between the real exchange rate and income per capita is favorable to the Balassa-Samuelson hypothesis. See, however, Bergin, Glick, and Taylor (2004), who point out that this association disappears in historical data going back fifty years or more.

${ }^{3}$ See Engel (1999) for further evidence indicating that the purchasing power parity does not hold for traded goods.

${ }^{4}$ For example, Choudhri and Khan (2005) using a sample of developing countries , and Ricci, MilesiFerretti and Lee (2008) using a larger sample including industrial and developing countries, show that the long-run effect of the traded-goods productivity differential on the real exchange rate (based on DOLS) is significant, but smaller than the predicted value. Also see Corsetti, Dedola and Leduc (2006), who use structural VAR to estimate the dynamic effects of traded-goods productivity shocks on the real exchange rates for G7 countries, and find that a permanent shock leads to a long-run depreciation of the real value of the currency for Italy and UK and no permanent effect for Germany, Japan and USA.
} 
Krugman (1980). This modification is suggested by new open economy macroeconomic models and can account for long-run departures from purchasing power parity for traded goods. The paper develops a basic modern version of the Balassa-Samuelson model, in which differentiated traded and nontraded goods are produced under monopolistic competition using only one factor, labor. To examine the long-run effects, the model is solved for its steady-state equilibrium. In this model, the adjustment of the terms of trade (the price of exported varieties relative to imported varieties) can significantly alter the effect of productivity changes on the real exchange rate.

The role of terms of trade changes in transmitting productivity shocks to the real exchange rate has already been examined in DGE models of open economies. A consensus has not emerged, however, on how the terms of trade and the real exchange rate respond to an improvement in the traded-goods productivity. In a DGE models of an open economy (calibrated to UK-Euro area), Benigno and Thoenissen (2003) find that an increase in the traded-goods productivity causes a deterioration in the UK terms of trade, which is sufficient to offset the effect of the productivity-induced appreciation in the relative price of nontraded goods and lead to a decrease in the real value of Sterling. In contrast, Corsetti, Dedola and Leduc (2004) develop a model (calibrated to the US economy), in which higher productivity in the traded goods sector, in fact, improves the terms of trade and thus increases the effect of the rise in the relative price of nontraded goods on the real exchange rate.

A primary goal of this paper is to explore the conditions that determine the sign and the magnitude of the effect of a productivity improvement in traded goods on the terms of trade as well as the real exchange rate. The elasticity of substitution between home and 
foreign traded goods (the Armington elasticity) plays a key role in determining these conditions. The paper's analysis identifies three critical intervals for the Armington elasticity. A rise in the productivity of traded goods increases the real exchange rate in the low and high intervals, but causes it to depreciate in the middle interval. This result occurs because the productivity increase improves the terms of trade in the low interval, thereby reinforcing the Balassa-Samuelson relative price effect; worsens the terms of trade in the middle interval sufficiently to more than offset the relative price effect; and causes a smaller term-of-trade deterioration in the high interval, which only partially offsets the relative price effect.

A quantitative version of the model with reasonable parameter values is used to identify the critical values of the Armington elasticity that separate the three intervals. We find that the borderline value between the middle and high intervals (but not the one between the low and middle intervals) lies well within the range of estimates of the elasticity suggested in the literature. This finding implies that Balassa-Samuelson hypothesis is fragile in that small variations in the Armington elasticity within a plausible range can make the effect of the productivity improvement on the real exchange rate negative or positive as well as small or large. Therefore, this finding provides a potential explanation of why tests of the Balassa-Samuelson hypothesis produce mixed results.

Following the standard DGE models, the paper's basic model assumes that the number of varieties is fixed. The paper, also, however, considers a variation that allows endogenous determination of the number of varieties. This modification introduces an additional channel in the transmission of productivity shocks to the real exchange rate. The role of this channel has been examined by a number of recent papers within models 
that include only traded goods. Allowing productivity to differ across firms, Ghironi and Melitz (2005) show that a shock to aggregate productivity causes (via entry and exit of firms in the domestic and foreign markets) persistent departures from PPP that are similar to the Balassa-Samuelson effects. Corsetti, Martin and Pesenti (2007) examine the implication of an endogenous number of varieties for the welfare effect of productivity changes under the traditional assumption of symmetric firms in each industry. ${ }^{5}$

This paper also assumes symmetric firms, but uses a model with nontraded as well as traded goods to explore how the adjustment in the number of varieties influences the relation between traded-goods productivity and the real exchange rate. The paper finds that the entry or exit of firms in the traded and nontraded goods sectors magnifies both the terms of trade and the relative price effects of productivity changes, and thus modifies the impact of a productivity improvement on the real exchange rate at different values of the Armington elasticity. The quantitative analysis shows, however, that the endogenous determination of the number firms does not significantly alter the results or the fragility of the Balassa-Samuelson hypothesis.

The basic model and its variations are discussed in section 2. The analytical solution of the model (based on linear approximation around the initial steady state) is used in section 3 to identify key factors that determine the effects of productivity changes on the terms of trade and the real exchange rate. Quantitative analysis is then undertaken in section 4 to explore the signs and magnitudes of these effects to variations in the values of key parameter within plausible ranges.

\section{Model}

\footnotetext{
${ }^{5}$ In a related paper, Corsetti, Martin and Pesenti (2008) examine the implication of endogenous varieties for the transfer problem.
} 
We consider a 2-country model with differentiated traded and nontraded goods and one factor, labor, which is perfectly mobile between the two sectors. The equations of the model for the home economy are discussed below. Symmetric equations are assumed for the foreign economy with an asterisk used to denote foreign variables and parameters. The lifetime utility of a representative household is given by $U_{t}=\sum_{s=t}^{\infty} \delta^{s-t} u\left[C_{s}, L_{s}\right]$, where $C_{s}$ and $L_{s}$ are the household's aggregate consumption index and labor supply. Our model allows for international financial transactions, but following the standard approach, we assume that there exists a debt-dependent transaction cost or a risk premium that induces a unique steady state with zero net foreign assets.

As the paper is concerned only with the long-run effects, we do not explicitly model the dynamics that would arise from nominal rigidities or international borrowing or lending. Therefore, we focus on the conditions required for steady-state equilibrium (since the time subscripts are not needed, they are omitted). ${ }^{6}$ All prices in the model are defined as real prices in terms of $C$ for the home relations and $C^{*}$ for the foreign relations. The real exchange rate is defined as the relative price of $C$ to $C^{*}$ (i.e., the number of units of $\mathrm{C}^{*}$ per unit of $\mathrm{C}$ or the real value of the home currency).

The single-period utility is assumed to be of the form:

$$
u(C, L)=\left(\frac{C^{1-\theta}}{1-\theta}-\frac{\psi L^{1+\mu}}{1+\mu}\right)
$$

with $C$ given by the following CES index:

$$
C=\left[\chi_{N}^{1 / v} C_{N}^{(v-1) / v}+\chi_{T}^{1 / v} C_{T}^{(v-1) / v}\right]^{v /(v-1)}, \quad \chi_{N}+\chi_{T}=1
$$

\footnotetext{
${ }^{6}$ The same conditions would also hold for short-run equilibrium in the model if there were flexible prices and financial autarky.
} 
where $C_{N}$ and $C_{T}$ are consumption baskets for the differentiated nontraded and traded goods, and $v$ is the elasticity of substitution between these baskets. The traded good basket is also assumed to be a CES index as follows:

$$
C_{T}=\left[\chi_{H}^{1 / \eta} C_{H}^{(\eta-1) / \eta}+\chi_{F}^{1 / \eta} C_{F}^{(\eta-1) / \eta}\right]^{\eta /(\eta-1)}, \quad \chi_{H}+\chi_{F}=1,
$$

where $C_{H}$ and $C_{F}$ are consumption bundles of domestic and foreign varieties of the traded good and $\eta$ is the (Armington) elasticity of substitution between the home and foreign bundles. The nontraded good basket and the traded good bundles are defined as

$$
\begin{gathered}
C_{N}=\left[\int_{0}^{n_{N}} C_{N}(i)^{(\sigma-1 / \sigma} d i\right]^{\sigma /(\sigma-1)}, \\
C_{H}=\left[\int_{0}^{n_{H}} C_{H}(j)^{(\sigma-1 / \sigma} d j\right]^{\sigma /(\sigma-1)}, C_{F}=\left[\int_{0}^{n_{F}} C_{F}\left(j^{*}\right)^{(\sigma-1 / \sigma} d j^{*}\right]^{\sigma /(\sigma-1)},
\end{gathered}
$$

where nontraded and traded varieties in the home economy are indexed by $i \in\left[0, n_{N}\right]$ and $j \in\left[0, n_{H}\right]$, foreign traded varieties are indexed by $j^{*} \in\left[0, n_{F}\right]$, and $\sigma$ is the elasticity of substitution between varieties within each aggregate.

The production functions for traded and nontraded varieties are

$$
Y_{N}(i)=A_{N} L_{N}(i), \quad Y_{H}(j)=A_{H} L_{H}(j)
$$

where $Y_{N}(i), L_{N}(i)$ and $A_{N}$ represent output, labor input and labor productivity for the nontraded good, and $Y_{H}(j), L_{H}(j)$ and $A_{H}$ are the corresponding variables for the home traded good..

Optimization by households leads to the following standard conditions:

$$
\begin{gathered}
w=\psi L^{\mu} / C^{-\theta}, \\
C_{N}=\chi_{N} C\left(p_{N}\right)^{-v}, \quad C_{T}=\chi_{T} C\left(p_{T}\right)^{-v},
\end{gathered}
$$




$$
\begin{gathered}
C_{H}=\chi_{H} C_{T}\left(p_{H} / p_{T}\right)^{-\eta}, \quad C_{F}=\chi_{F} C_{T}\left(p_{F} / p_{T}\right)^{-\eta} \\
C_{N}(i)=C_{N}\left(p_{N}(i) / p_{N}\right)^{-\sigma}, C_{H}(j)=C_{H}\left(p_{H}(j) / p_{H}\right)^{-\sigma}, C_{F}\left(j^{*}\right)=C_{F}\left(p_{F}\left(j^{*}\right) / p_{F}\right)^{-\sigma},(10)
\end{gathered}
$$

where $w$ denotes the real wage rate; $p_{N}(i), p_{H}(j)$ and $p_{F}\left(j^{*}\right)$ denote real prices of the varieties of the home nontraded and traded goods and the foreign traded good; $p_{T}, p_{N}$, $p_{H}$, and $p_{F}$ are, respectively, the real prices for the traded and nontraded goods baskets and the home and foreign bundles of the traded good. The price indices satisfy the following conditions implied by the minimization of unit costs of different consumption indices:

$$
\begin{gathered}
1=\left[\chi_{N} p_{N}^{1-\nu}+\chi_{T} p_{T}^{1-\nu}\right]^{1 /(1-v)}, \quad p_{T}=\left[\chi_{H} p_{H}^{1-\eta}+\chi_{F} p_{F}^{1-\eta}\right]^{1 /(1-\eta)}, \\
p_{N}=\left[\int_{0}^{n_{N}} p_{N}(i)^{1-\sigma} d i\right]^{1 /(1-\sigma)}, \\
p_{H}=\left[\int_{0}^{n_{H}} p_{H}(j)^{1-\sigma} d j\right]^{1 /(1-\sigma)}, \quad p_{F}=\left[\int_{0}^{n_{F}} p_{F}\left(j^{*}\right)^{1-\sigma} d j^{*}\right]^{1 /(1-\sigma)} .
\end{gathered}
$$

Optimal price setting by firms implies that

$$
p_{N}(i)=(\sigma /(\sigma-1)) w / A_{N}, p_{H}(j)=(\sigma /(\sigma-1)) w / A_{H}, p_{H}^{*}(j)=q p_{H}(j),
$$

where $q$ is the real exchange rate and $p_{H}^{*}(j)$ is the real price of the home variety in the foreign market (in terms of units of $C^{*}$ ). Each firm's output equals the demand for its variety:

$$
Y_{N}(i)=C_{N}(i), \quad Y_{H}(j)=C_{H}(j)+C_{H}^{*}(j),
$$

As net foreign assets equal zero in steady state, we also have balanced trade:

$$
p_{F} C_{F}=p_{H} C_{H}^{*}
$$


We consider two variants of the model. In the first variant, we make the standard assumption that the number of firms in each sector is fixed. The labor endowment constraint in this case is

$$
L=n_{N} L_{N}(i)+n_{H} L_{H}(j)
$$

In the second variant, the number of firms is determined endogenously in each sector. For this case we assume that fixed amounts of labor equal to $\phi_{N} / A_{N}$ and $\phi_{H} / A_{H}$ are required to produce a unit of a variety of the nontraded and traded goods, respectively. Entry or exit of firms in each industry ensures that the price of each variety also equals its average cost. Thus

$$
p_{N}(i)=\left(w / A_{N}\right)\left(\phi_{N} / Y_{N}(i)+1\right), \quad p_{H}(j)=\left(w / A_{H}\right)\left(\phi_{H} / Y_{H}(j)+1\right) .
$$

The endowment constraint is now revised as

$$
L=n_{N}\left(\phi_{N} / A_{N}+L_{N}(i)\right)+n_{H}\left(\phi_{H} / A_{H}+L_{H}(j)\right) .
$$

\section{Analytical Solution}

To solve for the response of the real exchange rate to productivity changes, we use a first-order log-linear approximation around the initial steady state. Setting initial real prices of all consumption indices equal to one by normalization, $\chi_{N}$ and $\chi_{T}$ represent shares of nontraded and traded goods in aggregate consumption while $\chi_{H}$ and $\chi_{F}$ are shares of home and foreign bundles in the traded good consumption basket. Similarly, $\chi_{N}^{*}, \chi_{T}^{*}, \chi_{H}^{*}$ and $\chi_{F}^{*}$ are the corresponding shares for the foreign economy.

Letting a hat over a variable denote the log deviation from its initial steady state value, and using (11) and the third equation in (14), we can express the rate of change of the real exchange rate as 


$$
\hat{q}=\chi_{N}\left(\hat{p}_{N}-\hat{p}_{T}\right)-\chi_{N}^{*}\left(\hat{p}_{N}^{*}-\hat{p}_{T}^{*}\right)+\beta \hat{\tau}
$$

where $\beta \equiv \chi_{H}-\chi_{H}^{*}\left(=\chi_{F}^{*}-\chi_{F}\right)$ represents home bias in the traded good consumption and $\tau \equiv p_{H} / p_{F}\left(=p_{H}^{*} / p_{F}^{*}\right)$ is the home terms of trade. In the absence of home bias ( $\beta=0$ ), (20) yields the familiar result of the standard Balassa-Samuelson model that the real exchange rate is determined by the home and foreign relative prices of the nontraded good.

Even without home bias, however, the present modified model differs from the standard model in two important respects. First, the traded good bundle includes imported goods (that are not produced domestically), and thus the terms of trade affect the relative price of the nontraded good in each country. Using the second equation in (11), we can decompose the rate of change in the nontraded-traded goods price ratio in the home economy as

$$
\hat{p}_{N}-\hat{p}_{T}=\hat{p}_{N}-\hat{p}_{H}+\chi_{F} \hat{\tau}
$$

Second, the price indices for the nontraded and home traded goods depend on the number as well as the prices of the varieties of each good. We can use (13) and the first two equations in (14) to state the relative price of the nontraded to home-traded good as ${ }^{7}$

$$
\hat{p}_{N}-\hat{p}_{H}=\hat{A}_{H}-\hat{A}_{N}+\left(\hat{n}_{H}-\hat{n}_{N}\right) /(\sigma-1)
$$

Now use (21) and (22) and the foreign counterparts of these equations to restate (20) as

$$
\begin{aligned}
\hat{q} & =\chi_{N}\left(\hat{A}_{H}-\hat{A}_{N}\right)-\chi_{N}^{*}\left(\hat{A}_{F}^{*}-\hat{A}_{N}^{*}\right)+\left(\chi_{N} \chi_{F}+\chi_{N}^{*} \chi_{H}^{*}+\beta\right) \hat{\tau} \\
& +\left[\chi_{N}\left(\hat{n}_{H}-\hat{n}_{N}\right)-\chi_{N}^{*}\left(\hat{n}_{F}-\hat{n}_{N}^{*}\right)\right] /(\sigma-1) .
\end{aligned}
$$

\footnotetext{
${ }^{7}$ To derive (22), note that in equilibrium (with the same price for all varieties of a good), $\hat{p}_{N}=\hat{n}_{N} /(\sigma-1)+\hat{p}_{N}(i)$ and $\hat{p}_{H}=\hat{n}_{H} /(\sigma-1)+\hat{p}_{H}(i)$ from (13) and $\hat{w}=\hat{p}_{N}(i)+\hat{A}_{N}=\hat{p}_{H}(i)+\hat{A}_{H}$ from the first two equations of (14).
} 
In (23), productivity changes affect the real exchange rate directly (via the first two terms) as well as indirectly by influencing the terms of trade and the number of firms (via the last two terms). The direct effects are the same as in the standard Balassa-Samuelson model. The present model adds indirect effects that can reverse or modify the results of the standard model.

We first consider the simple case, in which the number of firms is fixed and the indirect productivity effect involves only the adjustment (along the intensive margin) in the terms of trade for the existing sets of home and foreign traded varieties. Later, we explore how the results are affected by allowing adjustment (along the extensive margin) in the number of varieties in each sector.

\subsection{Fixed Number of Firms}

In this case we let $\hat{n}_{H}=\hat{n}_{N}=\hat{n}_{F}=\hat{n}_{N}^{*}=0$ and solve the model for $\hat{\tau}$. To simplify the solution, we assume that the utility parameters, substitution elasticities and the shares of nontraded goods in the home and foreign economies are the same (i.e., $\mu^{*}=\mu, \theta^{*}=\theta$ $v^{*}=v, \eta^{*}=\eta, \sigma^{*}=\sigma$ and $\left.\chi_{N}^{*}=\chi_{N}\right){ }^{8}$ As shown in the Appendix, we obtain

$$
\hat{\tau}=\frac{\left(\chi_{T} \kappa+\chi_{N} v\right)}{\Delta}\left(\hat{A}_{H}-\hat{A}_{F}^{*}\right)+\frac{\chi_{N}(\kappa-v)}{\Delta}\left(\hat{A}_{N}-\hat{A}_{N}^{*}\right),
$$

where $\kappa \equiv(1+\mu) /(\theta+\mu)$, and $\Delta \equiv 1-\left(\chi_{N} v+\chi_{T} \kappa\right)(1-\beta)-\eta(1+\beta)$. If $\Delta>0$, we get the case highlighted by Corsetti, Dedola and Leduc (2007), in which the terms of trade improve as a result of a productivity increase in the home traded good. If $\Delta<0$, on the other hand, we have the typical case where a productivity improvement in the home traded good worsens the terms of trade. In this case, as discussed below, a sufficiently

\footnotetext{
${ }^{8}$ However, to allow home bias, we do not assume that the shares of the home traded good in the home and foreign markets $\left(\chi_{H}, \chi_{H}^{*}\right)$ are the same.
} 
strong terms of trade effect produces the result that the increase in the traded good productivity depreciates the real exchange rate.

The condition determining the sign of $\Delta$ depends on a number of parameters. These conditions are simplified in the special case (often assumed in the BalassaSamuelson model), in which aggregate consumption is a Cobb-Douglas index of the consumption of traded and nontraded goods, and utility is a log-linear function of aggregate consumption or labor supply is inelastic. For this case, set $v=\kappa=1$ in (24) to get $\Delta=\beta-\eta(1+\beta) .{ }^{9}$ Now $\Delta$ is positive or negative if $\eta$, the Armington elasticity of substitution, is smaller or greater than $\beta /(1+\beta)$, which is less than $1 / 2$ (since $\beta<1$ ). ${ }^{10}$

To determine the total effect (i.e., the direct plus the indirect effect via the terms of trade) of a productivity change on the real exchange rate, use (24) to substitute for the value of $\hat{\tau}$ in (23), and let $\chi_{N}^{*}=\chi_{N}$, to obtain

$$
\begin{array}{r}
\hat{q}=\left[\chi_{N}+\frac{\left(\chi_{N}+\chi_{T} \beta\right)\left(\chi_{T} \kappa+\chi_{N} v\right)}{\Delta}\right]\left(\hat{A}_{H}-\hat{A}_{F}^{*}\right) \\
-\left[\chi_{N}-\frac{\left(\chi_{N}+\chi_{T} \beta\right) \chi_{N}(\kappa-v)}{\Delta}\right]\left(\hat{A}_{N}-\hat{A}_{N}^{*}\right) .
\end{array}
$$

As (25) shows, the change in the real exchange rate depends on the home-foreign productivity growth differentials for both the traded and nontraded goods. The coefficients of $A_{H}$ is clearly positive if $\Delta>0$. However, if $\Delta<0$, the sign of the coefficient depends on the relative importance of the Balassa-Samuelson effect $\left(\chi_{N}\right)$ and the terms of trade effect $\left(\left(\chi_{N}+\chi_{T} \beta\right)\left(\chi_{T} \kappa+\chi_{N} v\right) / \Delta\right)$.

\footnotetext{
${ }^{9}$ Note that $\kappa=1$ if either $\theta=1$ (in the log-linear utility case) or $\mu \rightarrow \infty$ (in the case of inelastic labor supply).

${ }^{10}$ The sign of $\Delta$ reflects the slope of the world excess demand curve for the home traded good, which depends on the relative strength of the wealth and substitution effects of change in its price relative to the foreign traded good. A lower value of $\eta$ decreases the substitution effect while a higher value of $\beta$ gives more weight to the (negative) home wealth than to the (positive) foreign wealth effect.
} 
In the present model, imperfect substitution between home and foreign goods represents the key departure from the standard Balassa-Samuelson framework. ${ }^{11}$ It is thus interesting to examine the role of $\eta$ in determining the effect of an increase in $A_{H}$ on the real exchange rate. For sufficiently low values for $\eta$, it is possible that $\Delta>0$. In this lower range, an increase in $A_{H}$ would improve the terms of trade and hence appreciate the real exchange rate. As $\eta$ increases, $\Delta$ would decrease and become negative for $\eta$ greater than some critical value. ${ }^{12}$ The terms of trade effect of $A_{H}$ would then become negative, and thus there may be an intermediate range of values for $\eta$ where the terms of trade effect is sufficiently strong to more than offset the Balassa-Samuelson effect. Hence, an increase in $A_{H}$ would depreciate the real exchange rate in this intermediate range. As $\eta$ keeps on increasing, however, the terms of trade effect would weaken (via $\Delta$ ) and this effect would be eventually dominated by the Balassa-Samuelson effect. Thus there would also be an upper range for $\eta$ where an $A_{H}$ increase would again appreciate the real exchange rate.

\subsection{Endogenous Number of Firms}

In this case, productivity changes also bring about changes in the number of varieties by inducing firm entry or exit. The appendix shows that the model can be solved for $\hat{\tau}, \hat{n}_{H}-\hat{n}_{N}$ and $\hat{n}_{F}-\hat{n}_{N}^{*}$ as follows:

$$
\hat{\tau}=\frac{\sigma\left(\chi_{T} \tilde{\kappa}+\chi_{N} \tilde{v}\right)}{(\sigma-1) \tilde{\Delta}}\left(\hat{A}_{H}-\hat{A}_{F}^{*}\right)+\frac{\sigma \chi_{N}(\tilde{\kappa}-\tilde{v})}{(\sigma-1) \tilde{\Delta}}\left(\hat{A}_{N}-\hat{A}_{N}^{*}\right)
$$

\footnotetext{
${ }^{11}$ The Balassa-Samuelson model can be viewed as a special case of the paper's model with $\eta \rightarrow \infty$, in which case the terms of trade effect approaches zero.

${ }^{12}$ Note that in the neighborhood of the critical value, the terms of trade effect is very large since $\Delta$ is close to zero.
} 


$$
\begin{aligned}
& \hat{n}_{H}-\hat{n}_{N}=\tilde{v}\left(\hat{A}_{H}-\hat{A}_{N}\right)+\frac{\chi_{F}(v-1)(\sigma-1)}{\sigma-v} \hat{\tau}, \\
& \hat{n}_{F}-\hat{n}_{N}^{*}=\tilde{v}\left(\hat{A}_{F}^{*}-\hat{A}_{N}^{*}\right)-\frac{\chi_{H}^{*}(v-1)(\sigma-1)}{\sigma-v} \hat{\tau},
\end{aligned}
$$

where $\tilde{\Delta} \equiv 1-\left(\chi_{N} \tilde{v}+\chi_{T} \tilde{\kappa}\right)(1-\beta)-\eta(1+\beta), \tilde{\kappa}=\kappa(\sigma-1) /(\sigma-\kappa)$, and $\tilde{v}=v(\sigma-1) /(\sigma-v)$. Comparison of (26) with (24) shows how the response of the terms of trade to productivity changes is altered when the number of firms is determined endogenously. The special case of $v=\kappa=1$ implies that $\tilde{\kappa}=\kappa, \tilde{v}=v$ and $\tilde{\Delta}=\Delta$. In this case, the critical parameter values for which the sign of the productivity effect on the terms of trade switches from positive to negative are the same under both fixed and endogenous number of firms. Endogenous variation in the number of firms, however, magnifies the productivity effect (regardless of whether it is positive or negative). ${ }^{13}$ Equations (27) and (28), which determine the change in the number of firms in the traded relative to the nontraded sector in the two countries, are also $\operatorname{simplified~if~} v=1$, in which case the coefficient of $\hat{\tau}$ equals zero in both equations.

The overall effect of productivity changes on the real exchange rate can be derived by substituting the values of $\hat{\tau}, \hat{n}_{H}-\hat{n}_{N}$ and $\hat{n}_{F}-\hat{n}_{N}^{*}$ from (26), (27) and (28) in (23). One interesting question is how endogenous determination of firms changes the overall productivity effect. There are two opposing effects. Consider, for example, a productivity improvement in the home traded good sector, which induces firm entry in this sector and lowers the price of the home traded good relative to both the nontraded and the foreign traded good. This change would appreciate the real exchange rate via the relative

\footnotetext{
${ }^{13}$ Note that with $\tilde{\kappa}=\kappa, \tilde{v}=v$ and $\tilde{\Delta}=\Delta$, the values of coefficients of both productivity terms in (26) are $\sigma /(\sigma-1)$ times those in (24).
} 
nontraded good price channel [this effect is reflected in the fourth term of (23)], but could lower it via the terms of trade channel. In the quantitative version below, we examine how the productivity effect under the assumption of an endogenous number of firms differs from that under a fixed number of firms over a plausible range of parameter values.

\section{Quantitative Analysis}

In this section, we use a quantitative version of the model to examine how different parameter values influence the effect of productivity changes on the terms of trade and the real exchange rate. ${ }^{14}$ We focus on variations in $\eta$, as this parameter plays a critical role in determining the sign and magnitude of the productivity effect. We first discuss our results for a set of baseline values for other model parameters, which are broadly consistent with ones generally assumed in the literature. We then explore the sensitivity of the results to departures from baseline values. The baseline values are assumed to be: $\beta=0.5, v=0.99, \theta=2, \mu=4, \chi_{N}=0.6, \sigma=8$.For our sensitivity analysis, we let $\beta$, $v, \theta$ and $\mu$ vary over a wide range of values. ${ }^{15}$

We assume a symmetric case where the home and foreign countries are of equal size, and normalize the initial steady state values of $C$ and $C^{*}$ to equal one. ${ }^{16}$ However, as (24) suggests, the results are not sensitive to this assumption of symmetry, and would also apply to a pair of countries of unequal size as long as the share of nontraded goods

\footnotetext{
${ }^{14}$ The nonlinear model is solved for the initial and the new steady state (after the productivity change) using the DYNARE program.

${ }^{15}$ The estimate of $\chi_{N}$ is based on the average consumption share of nontraded goods in many countries, and the value of $\sigma$ used is broadly consistent with estimates of the markup [which equals $\sigma /(\sigma-1)]$. We do not examine variations in these parameters in our sensitivity analysis.

${ }^{16}$ Given these normalizations and the choice of parameter discussed above, the value of $\psi$ is determined by (7) and (14), and values of $\phi_{H}$ and $\phi_{N}$ by (14) and (18) when the number of firms is endogenous.
} 
and the home bias is the same. ${ }^{17}$ As the traded goods sector is generally thought to be the key source of productivity improvements, the discussion of results below focuses on the effect of a permanent $10 \%$ increase in $A_{H} \cdot{ }^{18}$ The $10 \%$ increase allows us to examine the effect of a large productivity increase in a nonlinear model (which may not be accurately captured by linear approximations discussed above).

\subsection{Benchmark Results}

Let $\mathrm{E}\left(\tau, A_{H}\right)$ denote the elasticity of the home terms of trade, $\tau$, with respect to productivity in the home trade traded good sector, $A_{H}$, (i.e., percentage changes in $\tau$ divided by the percentage increase in $A_{H}$ ) generated by simulations of the quantitative model. Figure 1 shows how this elasticity is related to the Armington elasticity, $\eta$, in the baseline case. We let $\eta$ vary in the $(0,2.5)$ interval and illustrate the relation for the case of fixed number of firms (model 1) as well as the case of endogenous number of firms (model 2). The analytical solution suggests that the relation is discontinuous in both models at a certain value of $\eta$ (which, for given values of other parameters implies that $\Delta=0$ ). For each model, this critical value for $\eta$ is between 0.3 and 0.4 . The value of $\mathrm{E}\left(\tau, A_{H}\right)$ is positive below and negative above this critical value. In both regions, the elasticity increases in $\eta$, but its absolute value becomes very large as $\eta$ approaches the critical value from below or above. ${ }^{19}$ A value of $\eta$ close to the critical value would thus imply much volatility in the terms of trade and the real exchange rate.

\footnotetext{
${ }^{17}$ Given balanced trade, the same home bias would, however, imply different shares of imports in aggregate consumption for the home and foreign countries in the asymmetric case.

${ }^{18}$ As (25) indicates, the effect of a $10 \%$ increase in $A_{F}^{*}$ would be symmetric but opposite in sign.

19 The Corsetti-Dedola-Leduc case of the terms of trade improving in response to an increase in home traded-goods productivity requires a value of $\eta$ below the critical level. Note, however, that the critical
} 
Calibrations of new open economy models tend to assume a value for this elasticity between 0.5 and $1.5{ }^{20}$ It is noteworthy that this range excludes the values for which $\mathrm{E}\left(\tau, A_{H}\right)$ is positive or has a large absolute value. Thus, for $\eta$ greater than 0.5 , the productivity effect on the terms of trade is negative and not too strong. However, it is still possible that the terms of trade effect could be sufficiently large to more than offset the Balassa-Samuleson effect via the relative price of nontraded goods, and produce the result that traded-goods productivity improvement at home decreases the real value of the home currency.

Letting $\mathrm{E}\left(q, A_{H}\right)$ denote the elasticity of the real exchange rate, $q$, with respect to $A_{H}$ (i.e., percentage changes in $q$ divided by the percentage increase in $A_{H}$ ) computed for the baseline case, Figure 2 explores what values of $\eta$ would imply a negative or a positive value of this elasticity. The figure shows the relation between $\mathrm{E}\left(q, A_{H}\right)$ and $\eta$ for both models in the $(0.5,2.5)$ interval. ${ }^{21}$ For model $1, \mathrm{E}\left(q, A_{H}\right)$ is negative in the lower range of the interval, and increases in $\eta$, but it switches sign from negative to positive at a borderline value of $\eta$ close to 1.2. The corresponding borderline value for model 2 is approximately the same. The relation for model 2, however, is steeper than that for model 1. This result reflects the fact that the endogenous determination of the number of firms

value of the substitution elasticity between home and foreign traded goods would be higher in their model because of distribution services which drive a wedge between producer and consumer prices.

${ }^{20}$ Estimation of macroeconomic models typically yields an estimate of the elasticity close to the lower half of this range (e.g., see Bergin, 2004, Lubik and Schorfheide, 2005). Estimation of international trade models based on data at a disaggregated or multi-sectoral level (e.g., Hertel et al, 2004) leads to estimates of the elasticity that are much higher than the range assumed in macroeconomic models.

${ }^{21}$ We exclude the 0-0.5 interval, which lies below the typical range of estimates, and includes very large effects for values of $\eta$. close to the discontinuity. 
magnifies both the terms of trade and the relative price effects, but the degree of magnification for the terms of trade effect diminishes as $\eta$ increases.

In the standard Balassa-Samuelson model, there is no terms of trade effect and the elasticity of $q$ with respect to $A_{H}$ equals the share of nontraded goods, $\chi_{N}$. The elasticity for our model, $\mathrm{E}\left(q, A_{H}\right)$, is less than $\chi_{N}$ (which is 0.6 in our baseline model) because of the offsetting effect of the terms of trade adjustment. The terms-of-trade offset becomes smaller as $\eta$ increases because the rise in the elasticity of substitution implies that a smaller change in the terms of trade is necessary to absorb the increase in supply of the home traded good caused by the productivity improvement. As Figure 2 shows, $\mathrm{E}\left(q, A_{H}\right)$ remains much below 0.6 even at $\eta=2.5$. This result is consistent with the typical empirical finding that the estimated elasticity of the real exchange rate with respect to traded-goods productivity is significantly smaller than the share of nontraded goods.

\subsection{Sensitivity Analysis}

We next examine the sensitivity of results to a number of variations of the baseline case. We let $\beta$ (the home traded-goods bias) vary from 0.2 to 0.8 , and $v$ (the elasticity of substitution between traded and nontraded goods) from 0.5 to 1.5 . For both $\theta$ (the inverse of the intertemporal elasticity of substitution) and $\mu$ (the inverse of the elasticity of labor supply), we consider a range of values from 1 to 5 (which implies a range from $1 / 3$ to 1 for $\kappa$ ). The results of this sensitivity analysis are summarized in Table 1 for variations of the baseline case which set the value of each parameter at the upper or lower ends of its range. For each variation, the table shows $\mathrm{E}\left(q, A_{H}\right)$ at $\eta=0.5$ and $\eta=1.5$ as 
well as the borderline value of $\eta$ (i.e., the value for which $\left.\mathrm{E}\left(q, A_{H}\right)=0\right)$ for model 1 and model 2.

The results of the sensitivity analysis are similar for the two models. The table shows that for all variations, $\mathrm{E}\left(q, A_{H}\right)$ is negative for $\eta=0.5$ and positive for $\eta=1.5$. The borderline value of $\eta$, in fact, lies between 1.0 and 1.4 in both models. Thus the sign of the productivity effect on the real exchange rate switches form negative to positive over a narrow range of values of the Armington elasticity even when relatively high or low values of other parameters are assumed.

\section{Concluding Remarks}

The paper revisits the classic Balassa-Samuelson framework to explore how productivity changes affect the real exchange rate in a model that modifies the standard version to incorporate product differentiation based on the specifications of Armington and Krugman. In this model, a productivity improvement in the home traded goods sector increases the relative price of nontraded to (domestically-produced) traded goods, but has an ambiguous effect on the terms of trade. The real exchange rate appreciates in response to an increase in both the relative price and the terms of trade. Thus if the productivity improvement leads to lower terms of trade, the real exchange rate can appreciate or depreciate depending on whether the relative price effect outweighs the terms of trade effect or not.

The paper explores the conditions which determine the signs and the magnitudes of the two effects. Its analysis shows how the response of the terms of trade and the real exchange rate to the productivity improvement depends on various parameters, in particular, on the Armington elasticity. We identify three intervals for the Armington 
elasticity such that higher productivity in the home traded good appreciates the real value of the home currency in the low and high intervals, but depreciates it in the middle interval.

Quantitative analysis is use to estimate the productivity effect for different values of the Armington elasticity. One key finding is that the values of the elasticity required for the productivity improvement to cause a (small or large) depreciation or appreciation of the real exchange rate lie well within the range of estimates suggested in the macroeconomic literature. This result is not affected by relaxing the assumption (typically made in open-economy macroeconomic models) that the number of firms in each sector is fixed.

The paper's analysis thus provides a potential explanation of the empirical results that the effect of higher productivity in traded goods on the real exchange rate is often smaller than the share of nontraded goods (as predicted by the Balassa-Samuelson hypothesis), and sometimes even has the wrong sign. The paper suggests that variations in the Armington elasticity across trading partners or time periods could account for differences in the direction and the strength of the productivity effect.

As in the original Balassa-Samuelson analysis, the paper has focused on the longrun effects of productivity changes on the real exchange rate, and thus has abstracted from the role of nominal rigidities and the current account dynamics. There has also been much interest in the short- and medium-term effects of productivity shocks on the real exchange rate. Exploring the conditions that determine the pattern of the dynamic response of the real exchange rate to sectoral productivity shocks would be an interesting agenda for future research. 


\section{References}

Armington, Paul S., 1969, “A Theory of Demand for Products Distinguished by Place of Production,” IMF Staff Papers, 16, 159-76.

Balassa, Bela, 1964, “The Purchasing Power Parity Doctrine: A Reappraisal,” Journal of Political Economy, 72, 584-96.

Benigno, Gianluca, and Christoph Thoenissen, 2003, "Equilibrium Exchange Rates and Supply-Side Performance,” Economic Journal, 113, 103-24.

Bergin, Paul R., 2004, "How Well Can the New Open Economy Macroeconomics Explain the Exchange Rate and Current Account?” Mimeo, University of California at Davis.

Bergin, Paul, Reuven Glick, and Alan M. Taylor, 2004, "Productivity, Tradability, and the Long-Run Price Puzzle,” NBER Working Paper No. 10569.

Canzoneri, Matthew B., Robert E. Cumby, and Behzad Diba, 1999, "Relative Labor Productivity and the Real Exchange Rate in the Long Run: Evidence for a Panel of OECD Countries,” Journal of International Economics, 47, 245-66.

Choudhri, Ehsan U. and Mohsin S. Khan, 2005, "Real Exchange Rates in Developing Countries: Are Balassa-Samuelson Effects Present?” IMF Staff Papers, 52, 387409.

Corsetti, Giancarlo, Luca Dedola and Sylvain Leduc, 2006, "Productivity, External Balance and Exchange Rates: Transmission Mechanism among G7 Countries," NBER Working Paper No. 12483.

Corsetti, Giancarlo, Luca Dedola and Sylvain Leduc, 2007, "International Risk-Sharing and the Transmission of Productivity Shocks,” [ECB Working Paper Series, No. 308] Review of Economic Studies, forthcoming.

Corsetti, Giancarlo, Philippe Martin, and Paolo Pesenti, 2007, "Productivity, the Terms of Trade, and the 'Home Market Effect',” Journal of International Economics, 73 (1), 99-127.

Corsetti, Giancarlo, Philippe Martin, and Paolo Pesenti, 2008, "Varieties and the Transfer Problem: The Extensive Margin of Current Account Adjustment,” NBER Working Paper No. 13795.

Engel, Charles, 1999, “Accounting for US Real Exchange Rate Changes,” Journal of Political Economy, 107, 507-38. 
Ghironi, Fabio, and Marc J. Melitz, 2005, “International Trade and Macroeconomic Dynamics with Heterogeneous Firms,” Quarterly Journal of Economics, 120, 865-915.

Harrod, Roy, 1933, International Economics (London: Nisbet and Cambridge University Press).

Hertel, Thomas, David Hummels, Maros Ivanic, and Roman Keeney, 2004, "How Confident Can We Be in CGE-Based Assessments of Free Trade Agreements?” GTAP Working Paper No. 26 (March).

Krugman, Paul, 1980, "Scale Economies, Product Differentiation and the Pattern of Trade,” American Economic Review, 70, 950-9.

Lubik, Thomas, and Frank Schorfheide, 2005, “A Bayesian Look at New Open Economy Macroeconomics,” Mimeo. Johns Hopkins University and University of Pennsylvania.

Ricci, Luca Antonio, Gian Maria Milesi-Ferretti, and Jaewoo Lee, 2008, "Real Exchange Rates and Fundamentals: A Cross-Country Perspective,” IMF Working Paper No. WP/08/13.

Rogoff, Kenneth, 1996, “The Purchasing Power Parity Puzzle,” Journal of Economic Literature, 34, 647-668.

Samuelson, Paul A., 1964, “Theoretical Notes on Trade Problems,” Review of Economics and Statistics, 46, 145-54. 


\section{Appendix}

The appendix explains the derivation of equations (24), and (26)-(28). Let a bar denote the initial steady state value of a variable and a hat the log deviation around this value using a first-order log-linear approximation (i.e., $\hat{q}=(q-\bar{q}) / \bar{q})$. We set $\bar{p}_{N}=\bar{p}_{T}=\bar{p}_{H}=\bar{p}_{F}=\bar{n}_{N}=\bar{n}_{H}=\bar{A}_{N}=\bar{A}_{H}=1$ (the same normalization is used for the foreign counterparts of these variables).

From (7)-(9) and (11), obtain

$$
\begin{gathered}
\hat{C}=\hat{w} / \theta-\mu \hat{L} / \theta, \\
\hat{C}_{N}=\hat{C}-v \hat{p}_{N}, \\
\hat{C}_{T}=\hat{C}-v \hat{p}_{T}, \\
\hat{C}_{H}=\hat{C}_{T}-\eta\left(\hat{p}_{H}-\hat{p}_{T}\right), \\
\hat{C}_{F}=\hat{C}_{T}-\eta\left(\hat{p}_{F}-\hat{p}_{T}\right) . \\
0=\chi_{N} \hat{p}_{N}+\chi_{T} \hat{p}_{T}=\hat{p}_{N}-\chi_{T}\left(\hat{p}_{N}-\hat{p}_{T}\right)=\hat{p}_{T}+\chi_{N}\left(\hat{p}_{N}-\hat{p}_{T}\right), \\
\hat{p}_{T}=\chi_{H} \hat{p}_{H}+\chi_{F} \hat{p}_{F}=\hat{p}_{H}-\chi_{F} \hat{\tau}=\hat{p}_{F}+\chi_{H} \hat{\tau},
\end{gathered}
$$

Next, noting that $p_{N}(i)$ and $p_{H}(j)$ are the same for all $i$ and $j$, use (12)- (14) to get

$$
\begin{gathered}
\hat{p}_{N}=\hat{p}_{N}(i)-\hat{n}_{N} /(\sigma-1), \quad \hat{p}_{H}=\hat{p}_{H}(j)-\hat{n}_{H} /(\sigma-1), \\
\hat{w}=\hat{A}_{N}+\hat{p}_{N}(i)=\hat{A}_{H}+\hat{p}_{H}(j),
\end{gathered}
$$

which implies that $\hat{p}_{N}-\hat{p}_{H}=\hat{A}_{H}-\hat{A}_{N}+\left(\hat{n}_{H}-\hat{n}_{N}\right) /(\sigma-1)$.

Now use (A2)-(A9) to express

$$
\begin{gathered}
\hat{C}_{N}=\hat{C}-v \chi_{T}\left(\hat{A}_{H}-\hat{A}_{N}\right)-v \chi_{T} \chi_{F} \hat{\tau}-v \chi_{T}\left(\hat{n}_{H}-\hat{n}_{N}\right) /(\sigma-1), \\
\hat{C}_{H}=\hat{C}+v \chi_{N}\left(\hat{A}_{H}-\hat{A}_{N}\right)+\left(v \chi_{N} \chi_{F}-\eta \chi_{F}\right) \hat{\tau}+v \chi_{N}\left(\hat{n}_{H}-\hat{n}_{N}\right) /(\sigma-1),
\end{gathered}
$$




$$
\begin{gathered}
\hat{C}_{F}=\hat{C}+v \chi_{N}\left(\hat{A}_{H}-\hat{A}_{N}\right)+\left(v \chi_{N} \chi_{F}+\eta \chi_{H}\right) \hat{\tau}+v \chi_{N}\left(\hat{n}_{H}-\hat{n}_{N}\right) /(\sigma-1) . \\
\hat{w}=\chi_{N} \hat{A}_{N}+\chi_{T} \hat{A}_{H}+\chi_{T} \chi_{F} \hat{\tau}+\left(\chi_{T} \hat{n}_{H}+\chi_{N} \hat{n}_{N}\right) /(\sigma-1)
\end{gathered}
$$

Let $L_{H}$ and $L_{N}$ denote employment in sectors $H$ and $N$. Noting that under balanced trade and our normalization, $\bar{L}_{H} /\left(\bar{L}_{H}+\bar{L}_{N}\right)=\chi_{T}$ and $\bar{L}_{N} /\left(\bar{L}_{H}+\bar{L}_{N}\right)=\chi_{N}$, express

$$
\hat{L}=\chi_{T} \hat{L}_{H}+\chi_{N} \hat{L}_{N}
$$

Also, (16) implies that

$$
\hat{\tau}=\hat{C}_{F}-\hat{C}_{H}^{*}
$$

Fixed Number of Firms

In this case $\hat{n}_{H}=\hat{n}_{N}=0$. Noting that $\chi_{H}=\bar{C}_{H} /\left(\bar{C}_{H}+\bar{C}_{F}\right)$ and $\chi_{F}=\bar{C}_{F} /\left(\bar{C}_{H}+\bar{C}_{F}\right)$

under balanced trade and our normalizations, use (6) and (15) to obtain

$$
\begin{gathered}
\hat{L}_{N}+\hat{A}_{N}=\hat{Y}_{N}=\hat{C}_{N}, \\
\hat{L}_{H}+\hat{A}_{H}=\hat{Y}_{H}=\chi_{H} \hat{C}_{H}+\chi_{F} \hat{C}_{H}^{*} .
\end{gathered}
$$

Use (A10)-(A12) and (A15)-(A17), to express (A14) as

$$
\hat{L}=\hat{C}-\chi_{T} \hat{A}_{H}-\chi_{N} \hat{A}_{N}-\chi_{T} \chi_{F} \hat{\tau}
$$

Substitute the values of $\hat{w}$ from (A13) and $\hat{L}$ from (A18) in (A1) to obtain

$$
\hat{C}=\kappa\left(\chi_{N} \hat{A}_{N}+\chi_{T} \hat{A}_{H}+\chi_{T} \chi_{F} \hat{\tau}\right)
$$

where $\kappa \equiv(1+\mu) /(\theta+\mu)$. Now substitute the value of $\hat{C}$ from (A19) in (A12) to get

$$
\hat{C}_{F}=\left(\kappa \chi_{T}+v \chi_{N}\right) \hat{A}_{H}+(\kappa-v) \chi_{N} \hat{A}_{N}+\left(v \chi_{N} \chi_{F}+\eta \chi_{H}+\kappa \chi_{T} \chi_{F}\right) \hat{\tau}
$$

Using similar steps to solve the foreign-economy counterpart of the model, derive

$$
\hat{C}_{H}^{*}=\left(\kappa^{*} \chi_{T}^{*}+v^{*} \chi_{N}^{*}\right) \hat{A}_{F}^{*}+\left(\kappa^{*}-v^{*}\right) \chi_{N}^{*} \hat{A}_{N}^{*}-\left(v^{*} \chi_{N}^{*} \chi_{H}^{*}+\eta^{*} \chi_{F}^{*}+\kappa^{*} \chi_{T}^{*} \chi_{H}^{*}\right) \hat{\tau} .
$$


To derive equation (24) in the text, let $\kappa^{*}=\kappa, v^{*}=v, \eta^{*}=\eta$ and $\chi_{N}^{*}=\chi_{N}$ (note that $\chi_{T}^{*}=1-\chi_{N}^{*}$ ), substitute the values of $\hat{C}_{F}$ and $C_{H}^{*}$ from (A20) and (A21) in (A15) and then solve for $\hat{\tau}$.

\section{Endogenous Number of Firm}

In this case, (14) and (18) imply that $Y_{N}(i)=(\sigma-1) \phi_{N}$ and $Y_{H}(j)=(\sigma-1) \phi_{H}$. Thus

$$
\hat{Y}_{N}(i)=\hat{Y}_{H}(j)=0
$$

Use (6), (19) and (A22) to get

$$
\hat{L}_{N}+\hat{A}_{N}=\hat{n}_{N}, \quad \hat{L}_{H}+\hat{A}_{H}=\hat{n}_{H} .
$$

Also, noting that $\chi_{H}=\bar{C}_{H} /\left(\bar{C}_{H}+\bar{C}_{F}\right)$ and $\chi_{F}=\bar{C}_{F} /\left(\bar{C}_{H}+\bar{C}_{F}\right)$ under our normalization and balanced trade, obtain from (4), (5), (15), and (A22),

$$
\hat{n}_{N}=\psi \hat{C}_{N}, \quad \hat{n}_{H}=\psi\left(\chi_{H} \hat{C}_{H}+\chi_{F} \hat{C}_{H}^{*}\right),
$$

where $\psi \equiv(\sigma-1) / \sigma$. Now Use (A10)-(A12) and (A23)-(A24), to express (A14) as

$$
\hat{L}=\psi \hat{C}-\chi_{T} \hat{A}_{H}-\chi_{N} \hat{A}_{N}-\psi \chi_{T} \chi_{F} \hat{\tau} .
$$

Next, substitute the values of $\hat{w}$ from (A13) and $\hat{L}$ from (A25) in (A1) to obtain

$$
\hat{C}=\tilde{\kappa}\left[\psi\left(\chi_{N} \hat{A}_{N}+\chi_{T} \hat{A}_{H}\right)+\chi_{T} \chi_{F} \hat{\tau}\right]
$$

where $\tilde{k} \equiv k(\sigma-1) /(\sigma-k)$. Substitution of the value of $\hat{C}$ from (A26) in (A12) yields

$$
\begin{aligned}
\hat{C}_{F}= & \left(\tilde{\kappa} \chi_{T} / \psi+\tilde{v} \chi_{N} / \psi\right) \hat{A}_{H}+(\tilde{\kappa} / \psi-\tilde{v} / \psi) \chi_{N} \hat{A}_{N} \\
& +\left(\tilde{v} \chi_{N} \chi_{F}+\eta \chi_{H}+\tilde{\kappa} \chi_{T} \chi_{F}\right) \hat{\tau} .
\end{aligned}
$$

Similarly, solve the foreign-economy counterpart of the model to derive

$$
\begin{aligned}
\hat{C}_{H}^{*}= & \left(\tilde{\kappa}^{*} \chi_{T}^{*} / \psi+\tilde{v}^{*} \chi_{N}^{*} / \psi\right) \hat{A}_{F}^{*}+\left(\tilde{\kappa}^{*} / \psi-\tilde{v}^{*} / \psi\right) \chi_{N}^{*} \hat{A}_{N}^{*} \\
& -\left(\tilde{v}^{*} \chi_{N}^{*} \chi_{H}^{*}+\eta^{*} \chi_{F}^{*}+\tilde{\kappa}^{*} \chi_{T}^{*} \chi_{H}^{*}\right) \hat{\tau}
\end{aligned}
$$


Equation (26) in the text is derived by letting $\kappa^{*}=\kappa, v^{*}=v, \eta^{*}=\eta$ and $\chi_{N}^{*}=\chi_{N}$, substituting the values of $\hat{C}_{F}$ and $C_{H}^{*}$ from (A27) and (A28) in (A15), and then solving for $\hat{\tau}$.

Also make use of (A10)-(A12), (A15) and (A24) to obtain

$$
\begin{gathered}
\hat{n}_{N}=\psi\left(\hat{C}-v \chi_{T}\left(\hat{A}_{H}-\hat{A}_{N}\right)-v \chi_{T} \chi_{F} \hat{\tau}\right)-\left(v \chi_{T} / \sigma\right)\left(\hat{n}_{H}-\hat{n}_{N}\right), \\
\hat{n}_{H}=\psi\left(\hat{C}+v \chi_{N}\left(\hat{A}_{H}-\hat{A}_{N}\right)+\chi_{F}\left(v \chi_{N}-1\right) \hat{\tau}\right)+\left(v \chi_{N} / \sigma\right)\left(\hat{n}_{H}-\hat{n}_{N}\right) .
\end{gathered}
$$

Subtract (A29) from (A30), and simplify to get equation (27) in the text. Equation (28) can be similarly derived from the foreign counterparts of (A29) and (A30). 
Figure 1. $\mathrm{E}\left(\tau, A_{H}\right)$ Related to $\eta$

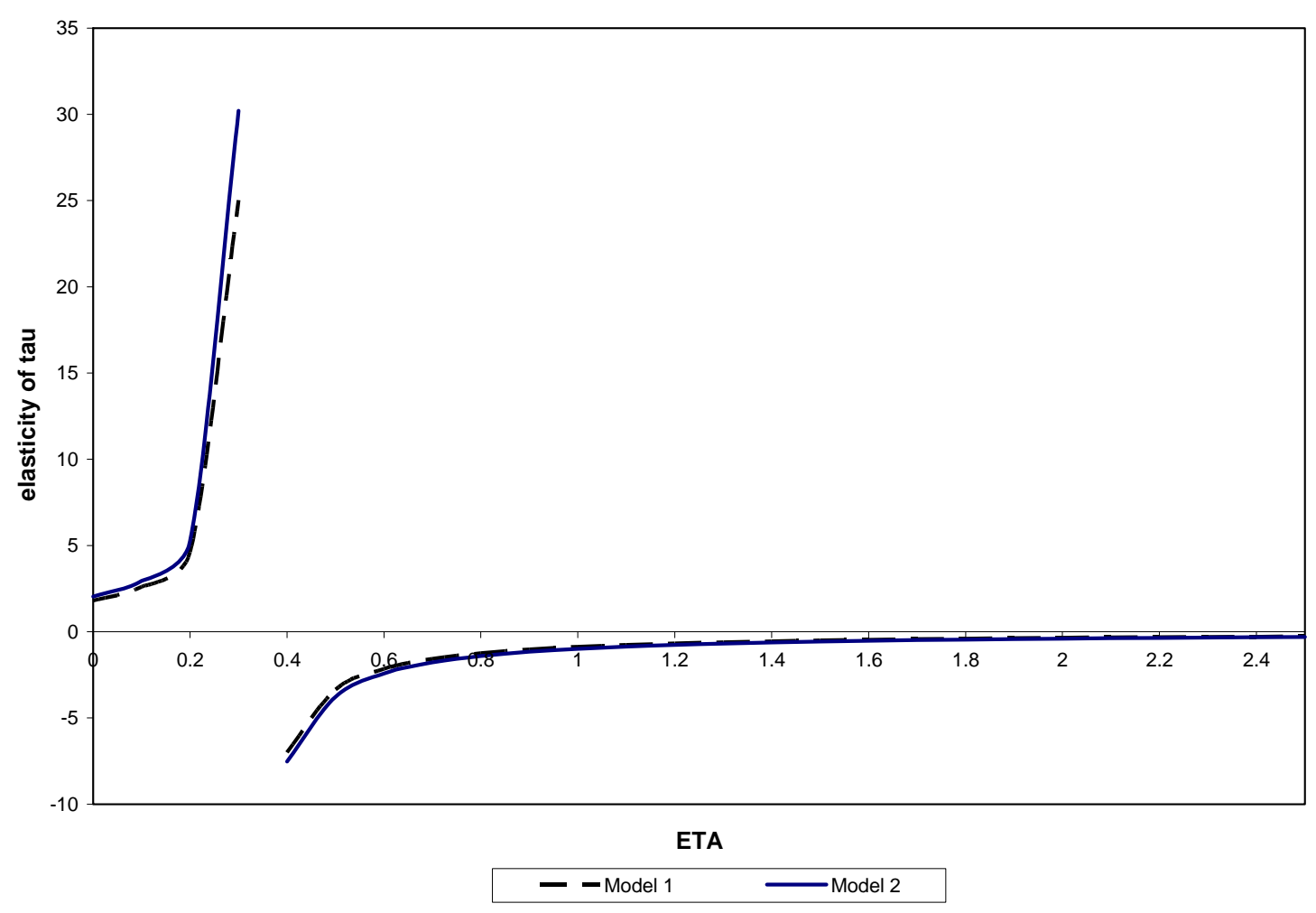

Figure 2. $\mathrm{E}\left(q, A_{H}\right)$ Related to $\eta$

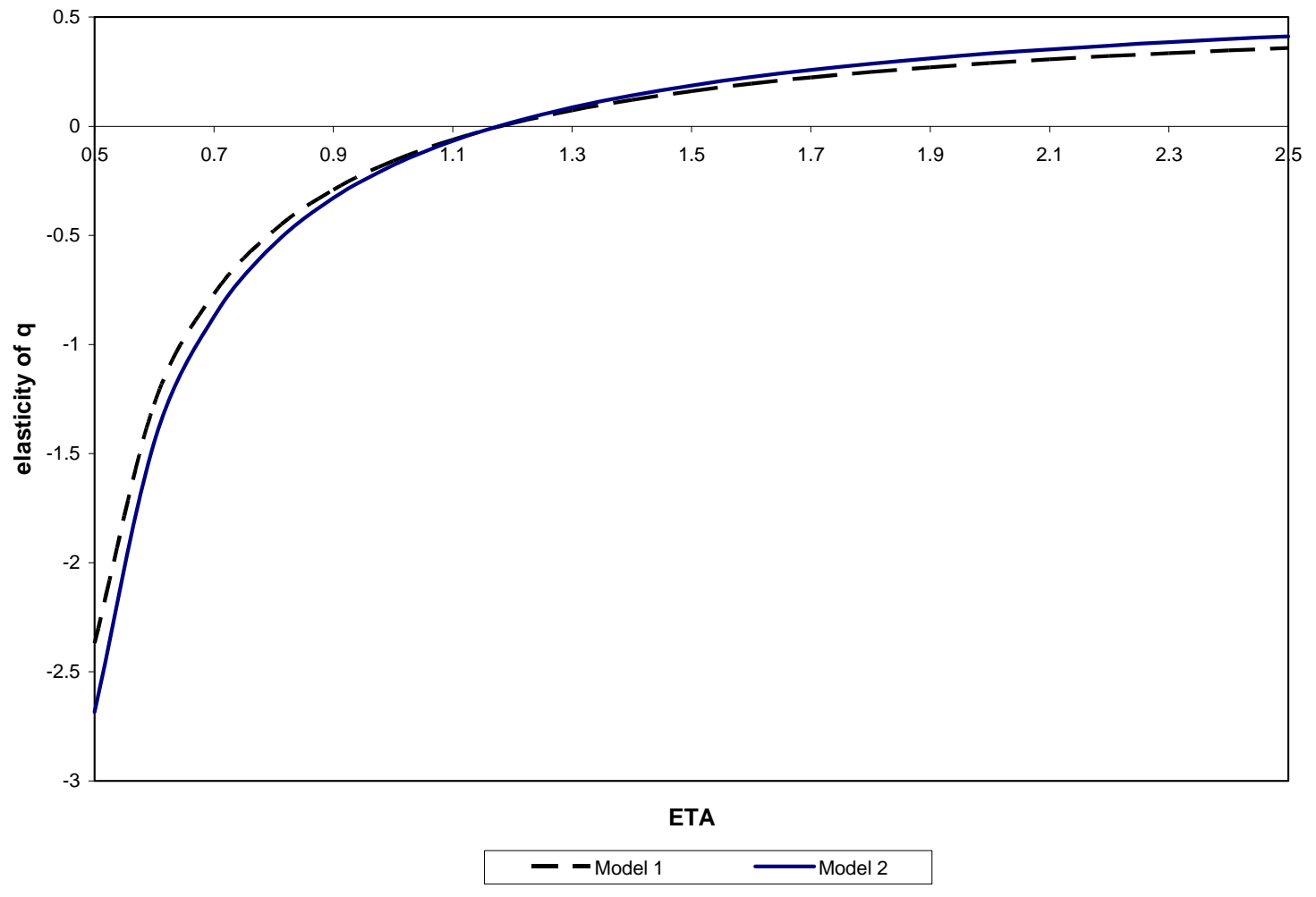




\section{Table 1. Sensitivity Analysis}

\begin{tabular}{|c|c|c|c|c|c|c|}
\hline & \multicolumn{3}{|c|}{ Model 1} & \multicolumn{3}{|c|}{ Model 2} \\
\hline & \multicolumn{2}{|c|}{ Elasticity of $q$} & \multirow{2}{*}{$\begin{array}{l}\text { Borderline } \\
\text { Value of } \eta\end{array}$} & \multicolumn{2}{|c|}{ Elasticity of $q$} & \multirow{2}{*}{$\begin{array}{l}\text { Borderline } \\
\text { Value of } \eta\end{array}$} \\
\hline & $\eta=0.5$ & $\eta=1.5$ & & $\eta=0.5$ & $\eta=1.5$ & \\
\hline \multicolumn{7}{|c|}{ Baseline Case } \\
\hline & -2.386 & 0.161 & 1.19 & -2.704 & 0.186 & 1.18 \\
\hline \multicolumn{7}{|c|}{ Variations } \\
\hline$\beta=0.8$ & -5.785 & 0.142 & 1.25 & -6.267 & 0.165 & 1.24 \\
\hline$\beta=0.2$ & -1.118 & 0.184 & 1.10 & -1.285 & 0.212 & 1.09 \\
\hline$v=0.5$ & -4.822 & 0.272 & 1.02 & -5.855 & 0.289 & 1.02 \\
\hline$v=1.5$ & -1.804 & 0.066 & 1.36 & -1.985 & 0.009 & 1.34 \\
\hline$\kappa=1 / 3$ & -3.477 & 0.231 & 1.08 & -3.985 & 0.269 & 1.06 \\
\hline$\kappa=1$ & -2.203 & 0.139 & 1.23 & -2.474 & 0.159 & 1.22 \\
\hline
\end{tabular}

Note: Elasticity of $q\left[\mathrm{E}\left(q, A_{H}\right)\right]$ represents percentage change in $q$ divided by percentage change in $A_{H}$ based on model simulation of a $10 \%$ change in $A_{H}$. The borderline value of $\eta$ represents the value for which the elasticity of $q$ equals zero. 